\title{
Brucellar arthritis: a study of 39 Peruvian families
}

\author{
EDUARDO GOTUZZO, ${ }^{1}$ CARLOS SEAS, ${ }^{1}$ JORGE G GUERRA ${ }^{1}$ \\ CARLOS CARRILLO, ${ }^{1}$ TOMÁS S BOCANEGRA, ${ }^{2}$ ARMANDO CALVO, \\ OSWALDO CASTAÑEA, AND GRACIELAS ALARCÓN ${ }^{2}$
}

From the 'Instituto de Medicina Tropical 'Alexander Von Humboldt', and the ${ }^{2}$ Department of Medicine ${ }^{0}$ (Rheumatology), School of Medicine, Universidad Peruana Cayetano Heredia, Lima, Perú; and the $\vec{\circ}$ ${ }^{3}$ Departments of Medicine and Epidemiology, Schools of Medicine and Public Health, University of Alabama at Birmingham, Birmingham, Alabama

SUMMARY A study was conducted to characterise the articular manifestation of Brucella $\stackrel{\vec{\circ}}{\circ}$ melitensis within a family in Peru. From January 1981 to June 1986, 39 families with 232 ir individuals were evaluated. Brucellosis was diagnosed in 118 family members (attack rate of $\mathscr{\odot}$ $50 \cdot 9 \%$ ). A lower attack rate was observed in children less than 10 years' old compared with other 은 age groups $(\mathrm{p}<0 \cdot 02)$. Complete clinical data were available in 92 of the 118 affected members. Moderate and severe forms of the diseases were more prevalent in women than in men $(41 \cdot 8 \% v \subseteq$ $13.5 \% ; \mathrm{p}<0.001)$. Twenty eight of the 92 patients developed some brucellar complications; the articular involvement was the most prevalent $(23.9 \%)$. Arthritis was also more common in $\varnothing_{\infty}$ women than in men $(34.5 \% \vee 8.1 \% ; \mathrm{p}<0.01)$. Children appeared to have less articular.involvement. Overall, the following pattern was observed: peripheral arthritis $(54.5 \%)$; unilateral sacroiliitis $(23.0 \%)$; mixed arthritis $(4 \cdot 5 \%)$, and spondylitis $(9 \cdot 1 \%)$. Spondylitis was seen only in the elderly with chronic brucellosis. Four patients developed extra-articular rheumatism. Within members of family groups, brucellar arthritis occurred less frequently than $\frac{\circ}{\odot}$ in individual patients from the same hospital. This suggests that many family cases were diagnosed in the early stages.

Key words: brucellosis, family studies.

Brucellosis is a zoonosis endemic in certain areas of the world, where it is considered a public health problem. ${ }^{1}$ Four species of the Brucella genus, each one with a different animal reservoir, are recognised as capable of causing human disease: $B$ melitensis (goats), $B$ abortus (cows), $B$ suis (hogs), and $B$ canis (dogs). ${ }^{2}$

Humans acquire brucellosis by handling contaminated animal products or by eating dairy products made of unpasteurised milk. ${ }^{34}$ The clinical manifestations of brucellosis are protean and include rheumatic complaints in $20-85 \%$ of the patients. The prevalence and pattern of musculoskeletal involvement depend on the strain of Brucella infecting the individual (it is more common with $B$ melitensis), the age of the patient, and the duration of the disease. ${ }^{5}$ Arthritis of the sacroiliac and

Accepted for publication 24 February 1987.

Correspondence to Dr E Gotuzzo, Universidad Peruana Cayetano Heredia, PO Box 5045, Lima 100, Perú. peripheral joints is more common in younger individuals and in acute disease, whereas spinal $\delta$ involvement usually occurs in the elderly and in those with chronic brucellosis.

Several outbreaks of brucellosis have been reported in individuals infected through a commono contaminated edible product ( $B$ melitensis) ${ }^{6-9}$ but brucellosis occurring within family groups has been $\sigma$ the subject of very few reports. ${ }^{10-12}$

The present study was conducted to determine the clinical characteristics of $B$ melitensis in a group of Peruvian families. Special emphasis was placed on the characterisation of the articular manifestations? in these individuals.

\section{Patients and methods}

This prospective study was conducted through the $\frac{\overparen{\rho}}{\mathbb{C}}$ collaborative efforts of the divisions of infectious $\cong$ diseases and tropical medicine and rheumatology of 
the Cayetano Heredia university hospital in Lima, Perú. Family groups were included if they fulfilled the following criteria: (a) proband with a definite diagnosis of brucellosis (positive blood, bone marrow and/or synovial fluid cultures and/or brucellar febrile agglutinins at a titre $\geqslant 1 / 160) ;(b)$ at least two affected family members within the same household; (c) complete pedigree data; $(d)$ interval between brucellosis in the proband and other family member(s) not longer than 120 days.

All afflicted individuals were evaluated by a rheumatologist for the presence or absence of musculoskeletal involvement: peripheral arthritis, sacroiliitis, spondylitis, extra-articular rheumatism, or combinations, as previously described..$^{513}$

The severity of brucellosis was graded according to the presence or absence of complications as mild (without complications), moderate (a non-fatal complication), and severe (a potentially fatal complication).

Table 1 Attack rate in brucellosis by age groups in 232 members of 39 families

\begin{tabular}{lccl}
\hline $\begin{array}{l}\text { Age group } \\
\text { (years) }\end{array}$ & Affected & Unaffected & $\begin{array}{l}\text { Attack rate } \\
(\%)\end{array}$ \\
\hline Under 10 & 11 & 31 & $26 \cdot 2$ \\
$10-19$ & 36 & 27 & $57 \cdot 1$ \\
$20-29$ & 25 & 19 & $56 \cdot 8$ \\
$30-39$ & 17 & 18 & $48 \cdot 6$ \\
$40-49$ & 9 & 6 & $60 \cdot 0$ \\
$50-59$ & 11 & 8 & $57 \cdot 9$ \\
Over 60 & 9 & 5 & $64 \cdot 3$ \\
& Total 118 & 114 & \\
\hline
\end{tabular}

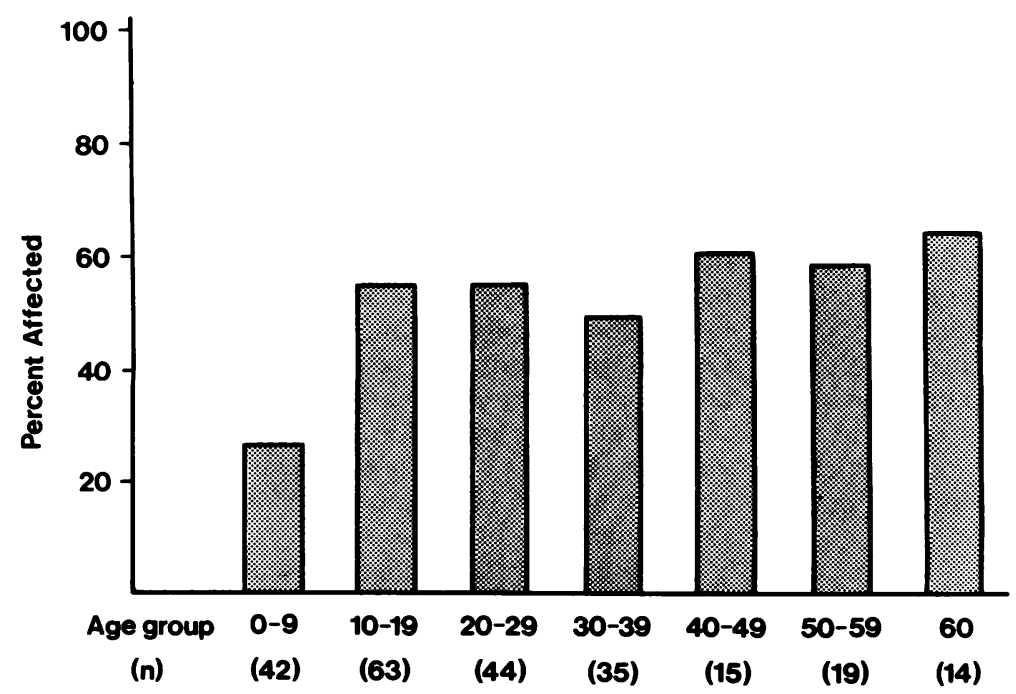

Fig. 1 Attack rate of brucellosis by age group in 39 Peruvian families.
The course of the disease was defined by the duration of symptoms as acute (eight weeks' duration), subacute or undulant (more than eight weeks and less than one year with intervening periods of remission during the course of the disease), and chronic (more than one year). ${ }^{4}$

\section{Results}

From January 1981 to June 198647 family groups were studied; eight did not meet the inclusion criteria and were excluded. A total of 232 individuals from 39 families was available for evaluation. Age distribution is shown in Table 1. Brucellosis was diagnosed in 118 family members, giving an attack rate of $50.9 \%$. The attack rate was similar in men and women $(51.1 \% v 50.7 \%)$, but it was lower in individuals younger than 10 when compared with the other age groups (Fig. $1, \mathrm{p}<0.02$ ).

Complete clinical data were available in $92(78 \%)$ of the 118 affected family members. The prevalence of acute, subacute, and chronic brucellosis was similar in both sexes and in all age groups (data not shown); moderate and severe disease was more prevalent in women than in men $(41.8 \% \vee 13.5 \%$, $\mathrm{p}<0.001)$ and in patients with subacute or chronic brucellosis compared with those with acute disease $(53.1 \%$ v $18.3 \%, \mathrm{p}<0.01)$.

Twenty eight $(30 \%)$ of the 92 patients developed 33 complications, musculoskeletal involvement being the most frequent (Table 2). Articular manifestations were more common in women than in men $(34.5 \% v 8 \cdot 1 \%, \mathrm{p}<0 \cdot 01)$. Children appeared to have articular involvement less often than adults, 
Table 2 Complications in the course of brucellosis in 92 members of 39 Peruvian families

\begin{tabular}{lrr}
\hline & No & $\%$ \\
\hline Musculoskeletal & 22 & $23 \cdot 9$ \\
Neurological & 3 & $3 \cdot 3$ \\
Hepatic & 3 & $3 \cdot 3$ \\
Dermatological & 2 & $2 \cdot 2$ \\
Haematological & 2 & $2 \cdot 2$ \\
Ocular & 1 & $1 \cdot 1$ \\
\hline
\end{tabular}

Table 3 Age distribution of brucellosis patients with articular involvement

\begin{tabular}{llcc}
\hline $\begin{array}{l}\text { Age group } \\
\text { (years) }\end{array}$ & $\begin{array}{l}\text { No of } \\
\text { cases }\end{array}$ & \multicolumn{2}{c}{ Articular involvement } \\
\cline { 3 - 4 } & & $n$ & $\%$ \\
\hline Under 15 & 22 & 3 & $13 \cdot 6$ \\
15-35 & 45 & 12 & $26 \cdot 7$ \\
$35-55$ & 15 & 4 & $26 \cdot 7$ \\
Over 55 & 10 & 3 & $30 \cdot 0$ \\
& Total 92 & 22 & $23 \cdot 9$ \\
\hline
\end{tabular}

Table 4 Pattern of articular involvement in 22 patients with brucellosis from 39 Peruvian families

\begin{tabular}{lc}
\hline & $\begin{array}{c}\text { Total No } \\
\text { (patients) }\end{array}$ \\
\hline $\begin{array}{l}\text { Peripheral arthritis* } \\
\quad \text { Monoarthritis }\end{array}$ & \multicolumn{1}{c}{12} \\
$\quad$ (knee 6, ankle, MTP PIP-hand, 1 each) & 9 \\
$\quad$ Polyarticular (pauciarticular) & 3 \\
Sacroiliitis (all unilateral) & \multicolumn{2}{|c}{5} \\
Spondylitis & 2 \\
Mixed arthritis & 1 \\
Extra-articular rheumatism* & 4
\end{tabular}

*Two patients had both peripheral arthritis and extra-articular rheumatism.

$\mathrm{MTP}=$ metatarsophalangeal; $\mathrm{PIP}=$ proximal interphalangeal.

but the differences were not statistically significant (Table 3). All patterns of articular involvement, as described by Gotuzzo et al,,$^{5}$ were seen (Table 4 ). Peripheral arthritis $(54.5 \%)$, usually affecting joints of the lower extremities, and unilateral sacroiliitis $(23 \%)$ were the most common patterns of joint involvement. Spondylitis was seen in the elderly with chronic brucellosis, and simultaneous involvement of the sacroiliac and peripheral joints in one patient. Four patients developed extra-articular rheumatism, two concomitantly with peripheral arthritis.

\section{Discussion}

There are few reports on the characteristics of brucellosis occurring in families. Spink studied nine family groups over a period of 16 years in an? endemic area for $B$ abortus, emphasising the re- $\overrightarrow{\vec{F}}$ latively low rate of symptomatic to infected individuals in these family groups, but the clinical등 characteristics of the symptomatic patients were not $\frac{\overline{\bar{s}}}{\bar{p}}$ the thrust of his communication. ${ }^{10}$ Feiz et al put $\widehat{\Phi}$ particular emphasis on the clinical features of this infection in children but did not present actual ${ }^{\infty}$ family data. ${ }^{11}$

Since brucellosis by $B$ melitensis biotype 1 is epidemic in the coastal cities of Perú, particularly in Lima, ${ }^{15}$ a unique opportunity for the study of the clinical characteristics of this disease when occurring? in family groups was available to us. In 39 families $\vec{~}$ afflicted with brucellosis, and followed up for $6 .-1$ months, half of the individuals became symptoma- ${ }^{\circ}$ tic, confirming the high degree of infectivity of $B_{\circ}^{\circ}$ melitensis. $^{2}{ }^{3}$ Subclinical infection such as that de- $\supset$ scribed with $B$ abortus ${ }^{10} 16$ was unlikely as serolo- $\vec{c}$ gical testing conducted in four of these families did not demonstrate seroconversion (data not shown).

There were clear differences in the attack rate $\mathscr{\infty}_{\infty}$ among the various age groups, with the lowest in the. ${ }^{.}$ under 10 and the highest in the over 55 year group. More than one factor is likely to explain these differences: less exposure to contaminated food, more efficient clearance of Brucella by the oropharyngeal lymphoid tissue of children, and the $\stackrel{\mathbb{Q}}{\stackrel{\mathbb{Q}}{2}}$ relatively low gastric $\mathrm{pH}$ among youngsters. On the $\overrightarrow{\vec{P}}$ other hand, a higher attack rate in older adults may also reflect a relatively deficient immune system in these individuals as part of the normal agingo process. ${ }^{17}$

In this study the prevalence of brucellosis was similar in both sexes, but the clinical manifestations, including articular involvement, were more severe in women. This observation has not been reportedô before to our knowledge, probably because $₹$ brucellosis in many places is an occupationalo disease $^{1819}$ occurring mainly in men. It may also be explained by the high prevalence of iron deficiency? anaemia in our female population, ${ }^{20}$ since micro- $N$ organisms of the Brucella genus show a greater degree of invasiveness and more rapid multiplica- $N$ tion when inoculated into iron deficient hosts. ${ }^{21 N}$ Genetically determined susceptibility factor(s) couldo also play a part in predisposing women to moreo severe disease and arthritis, but most immuno- $\overline{\mathbb{D}}$ genetic studies have not shown an association? between a given HLA specificity and osteoarticularo involvement in brucellosis. ${ }^{12} 22-24$

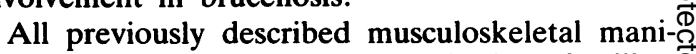
festations of brucellosis were seen in these families, $\stackrel{\mathbb{Q}}{\varrho}$ with peripheral arthritis and sacroiliitis occurringo mainly in the younger age groups and spondylitis 
more frequently in older adults, as seen by others. ${ }^{25} 26$ The lower prevalence of articular involvement in family members as compared with our patients in general may be due to earlier diagnosis in these families and the consequently reduced likelihood that afflicted individuals will go on to develop subacute or chronic disease.

In summary, the study of these families in a highly endemic area for brucellosis demonstrates the infectivity of $B$ melitensis compared with that of $B$ abortus. A lower attack rate in children and more severe disease in women were also observed. Finally, arthritis occurred less frequently within these families compared with patients with brucellosis from the same geographical area, suggesting that many cases were diagnosed earlier than usual. Exposure to a highly contaminated food product(s) is the most likely explanation for the clustering of cases within families.

We thank the physicians at Cayetano Heredia University Hospital who cared for these patients, and Mrs Nancy Clemmons and Ms Wanda Williamson for their expert technical assistance. Dr Carlos Carrillo is a recipient of an intramural research grant and $\mathrm{Dr}$ Graciela Alarcón of an arthritis biomedical research grant.

\section{References}

1 World Health Organisation. Elberg S S, ed. A guide to the diagnosis, treatment and prevention of human brucellosis. 1981: $\mathrm{VPH} / 81.31$.

2 Williams E. Brucellosis. Practitioner 1982; 226: 1507-14.

3 Young E J. Human brucellosis. Rev Infect Dis 1983; 5: 821-42.

4 Gotuzzo E, Carrillo C, Maguiña C, Guerra J. Importancia epidemiológica de alimentos previamente contaminados en la brucelosis humana en Lima, Perú [Abstract]. Taller Latinoamericano FAO/OMS. Lima, Perú Oct 1985.

5 Gotuzzo E, Alarcón G S, Bocanegra T S, et al. Articular involvement in human brucellosis: a retropective analysis of 304 cases. Semin Arthritis Rheum 1982; 12: 245-55.

6 Galbraith N S, Ross M S, De Mowbray R R, Payne D J H. Outbreak of Brucella melitensis type 2 infection in London. $\mathrm{Br}$ Med J 1969; i: 612-4.
7 Eckman M R. Bıucellosis linked to Mexican cheese. JAMA 1975; 232: 636-7.

8 Young E J, Suvannoparrat U. Brucellosis outbreak attributed to ingestion of unpasteurized goat cheese Arch Intern Med 1975; 135: $240-3$.

9 Arnow P M. Smaron M, Ormiste V. Brucellosis in a group of travelers to Spain. JAMA 1984; 251: 505-7.

10 Spink W W. Family studies on brucellosis. Am J Med Sci 1954; 222: 128-33.

11 Feiz J, Sabbaghian H, Miralai M. Brucellosis due to B melitensis in children. Clin Pediatr (Phila) 1978; 17: 904-7.

12 Alarcón G S, Gotuzzo E, Bocanegra T S, et al. Familial studies in human brucellosis. Tissue Antigens 1985; 26: 77-9.

13 Calvo A. Castañeda O, Gotuzzo E, Bocanegra T S, Carrillo C. Reumatismos extraarticulares en brucelosis. Proceedings of the IXth Pan American Congress of Rheumatology Buenos Aires. Argentina. 1986.

14 Scully R E, Mark E J, McNeely B U. Case records of the Massachusetts General Hospital (case 37-1986). N Engl J Med 1986; 315: 748-54.

15 Escalante J A. Held J R. Brucellosis in Perú. J Am Vet Med Assoc 1967: 155: 2146-52.

16 Spink W W. The nature of brucellosis. Minneapolis: University of Minnesota Press, 1956.

17 Ford P M. The immunology of aging. Clin Rheum Dis 1986: 12: 1-10.

18 Schirger A, Nichols D R, Martin W J, Wellman W E, Weed L A. Brucellosis: experiences with 224 patients. Ann Intern Med 1960; 52: 827-37.

19 Buchanan T M. Faber L C. Feldman R A. Brucellosis in the United States 1960-1972: an abattoir-associated disease. Part I. Clinical features and therapy. Medicine (Baltimore) 1974: 53: 403-13.

20 Gotuzzo E, Carrillo C. Guerra J, Llosa L. An evaluation of diagnostic methods for brucellosis-the value of bone marrow culture. J Infect Dis 1986; 153: 122-5.

21 Waring W S, Elberg S S, Schneider P, Green W. The role of iron in the biology of Brucella suis. J Bacteriol 1953; 66: 82-91.

22 Alarcón G S, Bocanegra T, Gotuzzo E, et al. Reactive arthritis associated with brucellosis: HLA studies. J Rheumatol 1981; 8: 621-5.

23 Alarcón G S, Gotuzzo E, Hinostroza S A, Carrillo C, Bocanegra T S, Espinoza L R. HLA studies in brucellar spondylitis. Clin Rheumatol 1985; 4: 312-4.

24 Hodinka L, Gömör B, Merétey K, et al. HLA-B27 spondyloarthritis in chronic brucellosis. Lancet 1978; i: 499.

25 Lifeso R M, Harder E, McCorkell S J. Spinal brucellosis. J Bone Joint Surg [Br] 1985; 67B: 345-51.

26 Ariza J, Gudiol F, Valverde J, et al. Brucellar spondylitis: a detailed analysis based on current findings. Rev Infect Dis 1985; 7: $656-64$. 